\title{
Application of multi yield analysis approaches to reservoir system
}

\begin{abstract}
Yield is used to characterise the capacity of a water resource. It is a fundamental watersupply planning concept, and an understanding of its attributes is critical for those who participate in water-supply issues. This study tends to carry out firm yield analysis by employing both the accumulated difference method (ADM) and reverse chronology method $(\mathrm{RCM})$ in order to ascertain the minimum storage capacity required to sustain the required yield of kainji reservoir system without interruption. In applying (ADM), the inflows were accumulated and the difference calculated. The minimum inflow within the year of record was determined to be the firm yield. The yield of $30 \times 109 \mathrm{~m}^{3}$ was hypothetically chosen to determine the minimum capacity to sustain it without interruption during the period under record. Similarly the firm yield analysis was also done by employing the method of reverse chronology (RCM) to confirm the result in the accumulated difference method. This method is based on the premise that what is the minimum volume that has to be in storage at the end of the previous year plus the inflow can meet the demand during the current year. This was carried out by starting with the last year of the record and working back to the first year and the difference between the inflow and the required yield was determined. The shortages were then observed form the difference obtained; the maximum shortage was then selected as the required capacity. The firm yield was determined to be $22.7283 \times 109 \mathrm{~m}^{3}$. The minimum capacity required to sustain a yield of $30 \times 109 \mathrm{~m}^{3}$ per annum (the average annual demand) without interruption during the period under record was determined to be $7.3431 \times 109 \mathrm{~m}^{3}$. The interaction between the reservoir elements were significant considering the correlation matrix applied.
\end{abstract}

Keywords: reservoir capacity, firm yield, inflow, accumulated, chronology, storage
Volume 4 Issue 3 - 2020

\author{
Mohammed Jiya Mamman,' Otache Y Matins² \\ 'Department of Agricultural Technology, Niger State College of \\ Agriculture Mokwa, Nigeria \\ ${ }^{2}$ Department of Agricultural and Bio- resource Engineering, \\ Federal University of Technology Minna, Niger State, Nigeria
}

Correspondence: Mohammed Jiya Mamman, Department of Agricultural Technology, Niger State College of Agriculture Mokwa, Niger State, Nigeria, Email ikwan 1565@gmail.com

Received: April 20, 2020 | Published: May 25, 2020

\section{Introduction}

A key parameter in designing reservoirs for water supply is the safe (or firm) yield, the maximum quantity of water that can be assured with some identified degree of confidence during a critical period. For example, the assured volume of water available to domestic users during low summer flows is considered firm yield. Determining the firm yield required to meet water supply objectives at a particular level of confidence depends upon the volume and timing of supply and demand. It is imperative to note that varying, hydrometeorological dynamics leads to variation in key reservoir variables like the inflow, storage and outflow; because of this water managers face the challenge of making available adequate quantities of water for drinking, agricultural and others vis-a-vis the geometrically increasing population pressure and socio-economic development, increase the needs and demands for particular water flows. ${ }^{1}$ The role of water-storage reservoirs, therefore, is to impound water during periods of higher flows, thus preventing flood disasters, and then permit gradual release of water during periods of lower flows.

According to Jose ${ }^{2}$ the reservoir yield, denoted by $\mathrm{Y}$, is the amount of water to be released whenever there is availability. The reservoir release at time $t(\mathrm{Dt})$ is the volume effectivelyliberated from the reservoir to meet the demand. It is less than or equal to the yield (Y) and depends on the reservoir content. When the reservoir contents exceed the reservoir capacity, there is uncontrolled outflow, or spill. The outflow is the summation of all water that leaves the reservoir as release, evaporation or spill. Yield is used to characterise the capacity of a water resource to serve as a long-term water supply. It is a fundamental water-supply planning concept, and an understanding of its attributes is critical for those who participate in water-supply issues. In the context of surface-water resources, yield is often synonymous with safe yield or firm yield. Safe yield or firm yield in the context of water reservoirs is defined as the maximum quantity of water which can be guaranteed during a critical dry period. ${ }^{3}$ Surface-water yield depends primarily on inflows and storage. In the case of an unregulated stream, the firm yield is often conceptualised as the minimum historical flow during a specified time period. It is important that yield analyses consider normal seasonal demand patterns; how demand varies during periods of drought in response to the drought itself and to applicable conservation measures; and that each drought has an individual signature defining the onset, critical period, duration, and precipitation/runoff variables, which may vary significantly among different drought events.

Drought and shortage of fresh water is currently an important limitation of water resources development. While in last decades a great deal of effort is increasingly diverted towards the use of poor quality water, the issues related to the storage and management of fresh water have not yet been properly addressed. The regulation of stochastically fluctuating flows of a natural stream by the conservation storage of a reservoir is a classical problem, known for thousands of years. Many studies have been performed with many different methods and different results for the relationship between storage capacity and target draft, which is defined as firm yield for a failurefree operation over a fixed service period. 
Various definitions of yield and risk or reliability of obtaining this yield from a reservoir have been suggested Gupton, ${ }^{4}$ which mainly depend on stream flow characteristics, storage capacity, evaporation losses, and reservoir service life. The data collected from the operation of the existing storage reservoirs, could offer valuable information for the better allocation and management of water rates for the future use. Others have successfully used the probability matrix method for different purposes. Gupton ${ }^{4}$ employed the matrix probability method through the multiplication of matrix by itself to obtain a two-year ratings transitionmatrix, which provides the desired default probabilities. Similarly, Rafecas et al., ${ }^{5}$ used the probability matrix method, by sorting the simulated data into a matrix, to calculate probability system by means of MonteCarlo simulations. Rosenberg and Werman ${ }^{6}$ have also used the probability distribution matrix method to extract and represent the motion displacement between two images while Saei et al., used the improved sequent peak algorithm (SPA) methods and probability matrix method and provided ultimately appropriate control curves to obtain various combinations of the quantity of demand and functional indices. The obtained results display a good accordance between the results obtained by SPA and probability matrix methods.

The traditional approach is to describe reservoir yield as assured, safe or sustainable, without these terms being appropriately defined. Considering climatic change dynamics of late, incidences of late rains have resulted in severe droughts. For example, as stated by Alcamo and Henrichs, ${ }^{7-9}$ tropical semi-arid river basins are generally subject to strong intra-annual and inter-annual rainfall variability and are among the areas most vulnerable to climate change. So, to what extent can the design yields of major dams in the country be said to be safe, assured, or sustainable?

A serious misinterpretation of firm yield (defined as the maximum quantity of water which can be guaranteed during a critical dry period) arises when a high degree of exploitation of the resource is involved. If say, a drought occurs is more severe than the worst drought used for the analysis, the system may not be able to sustain the calculated firm yield for many years during which the inflow are either less than the required high abstraction rate, or insufficient to build up sufficient storage in the reservoir to sustain the yield during subsequent low runoff periods. Thus, there is a high tendency of the reservoir not to be able to meet the design yield before the system recovers. Hence, from a theoretical point of view, the yield is far from being firm or assured.

This notion does not in any plausible way provide any information on the degree of assurance associated with the yield and too, it is also non - optimal for both maximum water yield and economic benefit. In additional, the calculated yield is a function of the worst historical drought and therefore requires a re- assessment each time a drought more severe than the previously worst recorded drought occurs. Interestingly too, the definitions of warm - up periods most often times is skewed: it is primarily defined on the assumption that it is solely related to the time taken for the initial yield of the reservoir Under conditions of high abstraction rates it is possible that the yield from a reservoir that fills soon after its construction may nevertheless at some later date enter a drought period more severe than the design drought. The simplicity of this definition belies two "complicating" factors. First, yield changes as watershed conditions, such as land use and ground-water-surface-water interactions, evolve. Second, yield is uncertain because of the inability to know the severity and duration of future drought periods. ${ }^{3}$

The most important aspect of the reservoir planning is to estimate the quantity of water likely to be available in the river from year to year and then seasons to season. The aim of this study therefore is to employ two methods of calculating yield i.e. Accumulated Difference Method and the Reverse Chronology Method in determiningrequired yield of the reservoir and to compare the result of the two methods.

\section{Materials}

The hydrological data employed for this study were stream flow, rainfall, and reservoir level and evaporation records.

\section{The study area}

The study area is located in Kainji, within latitude $9.54 \mathrm{~N}$ and $4.38 \mathrm{E} \mathrm{E}{ }^{10}$ The average rainfall is $2200 \mathrm{~mm}$ and the inflow peaked at 4000 to $6000 \mathrm{~m}^{3} / \mathrm{sec}$ in the month of September withaverage daily flow of $2280 \mathrm{~m}^{3} / \mathrm{sec}$

\section{Data base}

The data used for this study were twenty five years river inflow, fifty years rainfall data, fourty five years outflow and fourty one year's lake evaporation (1990-2014, 1965-2014, 1969-2013, and 1074-2014) respectively.

\section{Firm yield analysis}

The firm yield analysis was done by employing both the accumulated difference method (ADM) and reverse chronology method (RCM) this is to ascertain the minimum storage capacity required to sustain the required yield or demand (ratio of the mean annual flow) without interruption. The (ADM) was chosen on the basis of its simplicity in application; it provides answers in single calculation, and provide more reliable answers since it analysis is based on the historical inflow. This method has advantage over the trial and error method which is more labourious as the analysis has to do with a lot of trials and error. In applying (ADM), the inflows were accumulated and the difference calculated. The minimum inflow within the year of record was determined to be the firm yield. ${ }^{11}$ The yield of $30 \times 10^{9} \mathrm{~m}^{3}$ (the average annual demand) was hypothetically chosen to determine the minimum capacity to sustain it without interruption during the period under record. Similarly the firm yield analysis was also done by employing the method of reverse chronology (RCM) to confirm the result in the accumulated difference method. This method is based on the premise that what is the minimum volume that has to be in storage at the end of the previous year plus the inflow can meet the demand during the current year. ${ }^{10}$ This was carried out by starting with the last year of the record and working back to the first year and the difference between the inflow and the required yield was determined. The shortages were then observed form the difference obtained; the maximum shortage was then selected as the required capacity.

\section{Yield analysis}

The result of firm yield analysis employing Accumulated Difference method and Reverse Chronology method are as presented in Tables $1 \& 2$ respectively.

Tables $1 \& 2$ shows the firm yield analysis of Kainji reservoir system. In Table 1 accumulated difference method of firm yield analysis was adopted and in Table 3 the reverse chronology method was adopted. The firm yield was determined to be $22.7283 \times 10^{9} \mathrm{~m}^{3}$. The minimum capacity required to sustain a yield of $30 \times 10^{9} \mathrm{~m}^{3}$ per annum (the average annual demand) without interruption during the period under record was determined to be $7.3431 \times 10^{9} \mathrm{~m}^{3}$. Safe Yield (Firm Yield) is the amount of water that is supplied for a critical period. It is a guaranteed amount during this critical period. 
Table I Firm yield analysis with accumulated difference method

\begin{tabular}{|c|c|c|c|c|c|c|}
\hline year & Inflow $\left(\times 10^{9} \mathrm{~m}^{3}\right)$ & Cum. inflow & Cum. mean & Cum. required & Cum. difference & Range \\
\hline 1 & 22.7283 & 22.7283 & 35.88746 & 30 & 7.2717 & -37.2717 \\
\hline 2 & 29.054 & 51.7823 & 71.77486 & 60 & 8.2177 & -68.2177 \\
\hline 3 & 27.0207 & 78.803 & 107.6623 & 90 & 11.197 & -101.197 \\
\hline 4 & 23.6132 & 102.4162 & | 43.5497 & 120 & 17.5838 & -137.584 \\
\hline 5 & 36.9393 & 139.3555 & |79.437| & 150 & 10.6445 & -160.645 \\
\hline 6 & 37.3431 & 176.6986 & 215.3245 & 180 & 3.3014 & $-|83.30|$ \\
\hline 7 & 42.3901 & 219.0887 & 251.2119 & 210 & 9.0887 & -200.911 \\
\hline 8 & 29.9048 & 248.9935 & 287.0993 & 240 & 8.9935 & -231.007 \\
\hline 9 & 42.9209 & 291.9144 & 322.9867 & 270 & 21.9144 & -248.086 \\
\hline 10 & 45.005 & 336.9194 & $358.874 I$ & 300 & 36.9194 & $-263.08 I$ \\
\hline II & 38.2784 & 375.1978 & 394.7615 & 330 & 45.1978 & -284.802 \\
\hline 12 & 39.6647 & 414.8625 & 430.6489 & 360 & 54.8625 & -305.138 \\
\hline 13 & 34.3091 & 449.1716 & 466.5363 & 390 & 59.1716 & -330.828 \\
\hline 14 & 33.422 & 482.5936 & 502.4237 & 420 & 62.5936 & -357.406 \\
\hline 15 & 36.1986 & 518.7922 & 538.3111 & 450 & 68.7922 & -381.208 \\
\hline 16 & 32.5784 & 551.3706 & 574.1985 & 480 & 71.3706 & -408.629 \\
\hline 17 & 32.5414 & 583.912 & 610.0859 & 510 & 73.912 & -436.088 \\
\hline 18 & 40.3183 & 624.2303 & 645.9733 & 540 & 84.2303 & -455.77 \\
\hline 19 & 42.0173 & 666.2476 & 681.8607 & 570 & 96.2476 & -473.752 \\
\hline 20 & 37.9217 & 704.1693 & $7|7.748|$ & 600 & 104.1693 & -495.831 \\
\hline 21 & 45.1334 & 749.3027 & 753.6355 & 630 & II9.3027 & -510.697 \\
\hline 22 & 35.3213 & 784.624 & 789.5229 & 660 & 124.624 & -535.376 \\
\hline 23 & 39.8024 & 824.4264 & 825.4103 & 690 & 134.4264 & -555.574 \\
\hline 24 & 40.5225 & 864.9489 & 861.2977 & 720 & | 44.9489 & -575.05 I \\
\hline 25 & 32.2375 & 897.1864 & 897.1851 & 750 & 147.1864 & -602.814 \\
\hline
\end{tabular}

Key- cum=cumulative

Table 2 Firm yield analysis with the reverse chronology method

\begin{tabular}{llllll}
\hline year & Inflow $\left(\times 10^{9} \mathbf{~ m}^{3}\right)$ & Yield required & Difference & Short & Max short \\
\hline 25 & 22.7283 & 30 & -7.2717 & 7.2717 & 7.2717 \\
24 & 29.054 & 30 & -0.946 & 0.946 & 7.2717 \\
23 & 27.0207 & 30 & -2.9793 & 2.9793 & 7.2717 \\
22 & 23.6132 & 30 & -6.3868 & 6.3868 & 7.2717 \\
21 & 36.9393 & 30 & 6.9393 & 0 & 7.2717 \\
20 & 37.3431 & 30 & 7.3431 & 0 & 7.2717 \\
19 & 42.3901 & 30 & 12.3901 & 0 & 7.2717 \\
18 & 29.9048 & 30 & -0.0952 & 0.0952 & 7.2717 \\
17 & 42.9209 & 30 & 12.9209 & 0 & 7.2717 \\
16 & 45.005 & 30 & 15.005 & 0 & 7.2717 \\
15 & 38.2784 & 30 & 8.2784 & 0 & 7.2717 \\
\hline
\end{tabular}

Citation: Mamman MJ, Matins OY.Application of multi yield analysis approaches to reservoir system. Int J Hydro. 2020;4(3): 100-104. DOI: I0.15406/ijh.2020.04.00232 


\begin{tabular}{llllll}
\multicolumn{2}{l}{ Table Continued... } \\
\hline year & Inflow $\left(\times 10^{9} \mathbf{~ m}^{3}\right)$ & Yield required & Difference & Short & Max short \\
\hline 14 & 39.6647 & 30 & 9.6647 & 0 & 7.2717 \\
13 & 34.3091 & 30 & 4.3091 & 0 & 7.2717 \\
12 & 33.422 & 30 & 3.422 & 0 & 7.2717 \\
11 & 36.1986 & 30 & 6.1986 & 0 & 7.2717 \\
10 & 32.5784 & 30 & 2.5784 & 0 & 7.2717 \\
9 & 32.5414 & 30 & 2.5414 & 0 & 7.2717 \\
8 & 40.3183 & 30 & 10.3183 & 0 & 7.2717 \\
7 & 42.0173 & 30 & 12.0173 & 0 & 7.2717 \\
6 & 37.9217 & 30 & 7.9217 & 0 & 7.2717 \\
5 & 45.1334 & 30 & 15.1334 & 0 & 7.2717 \\
4 & 35.3213 & 30 & 5.3213 & 0 & 7.2717 \\
3 & 39.8024 & 30 & 9.8024 & 0 & 7.2717 \\
2 & 40.5225 & 30 & 10.5225 & 0 & 7.2717 \\
1 & 32.2375 & 30 & 2.2375 & 0 & 7.2717
\end{tabular}

\section{Correlation matrix for reservoir elements}

The results of the interaction between reservoir elements i.e., rainfall, evaporation, inflow outflow and reservoir draw - down are as presented in table below.

Table 3 shows the correlation matrix between the reservoir elements. The Pearson correlation between the rainfall and evaporation is -0.85207 , between rainfall and outflow is -0.50316 and between rainfall and draw-down is -0.75889 , between evaporation and inflow is -0.28596 this indicates strong but negative correlation between the elements. Similarly the correlation between evaporation and outflow is 0.366305 , and between inflow and draw- down is 0.0451922 . Indicating strong influence of the reservoir elements on one another at 0.05 probability.

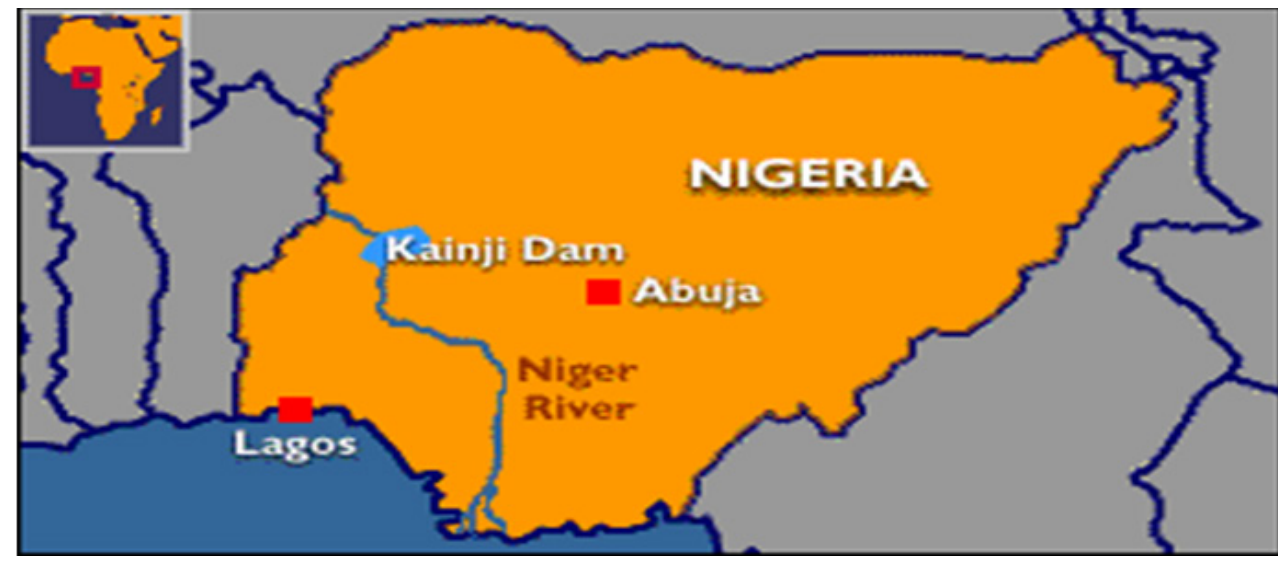

Figure I Location of Kainji Hydroelectric Dam.

Table 3 Correlation matrix for reservoir elements

\begin{tabular}{|c|c|c|c|c|c|}
\hline & Rainfall & Evaporation & Inflow & Outflow & Draw-down \\
\hline Rainfall & 1 & $-0.85207^{*}$ & 0.062914 & $-0.50316^{*}$ & $-0.75889 *$ \\
\hline Evaporation & & I & $-0.28596 *$ & 0.366305 & 0.650348 \\
\hline Inflow & & & I & $0.0578|3| *$ & $0.0451922 *$ \\
\hline Outflow & & & & I & 0.42106 \\
\hline Draw -Down & & & & & 1 \\
\hline
\end{tabular}

Correlation is significant at 0.05 level of probability; cell contents are Persian Correlation, values with * indicate that elements are significant at $5 \%$ probability 


\section{Conclusion}

The firm yield was determined by employing both the accumulated difference method (ADM) and reverse chronology method (RCM) this is to ascertain the minimum storage capacity required to sustain the required yield or demand without interruption. The firm yield was determined to be $22.7283 \times 10^{9} \mathrm{~m}^{3}$. The minimum capacity required to sustain a yield of $30 \times 10^{9} \mathrm{~m}^{3}$ per annum (the average annual demand) without interruption during the period under record was determined to be $7.3431 \times 10^{9} \mathrm{~m}^{3}$. The result of the two method adopted were the same. The correlation matrix describes the strong interaction between the reservoir elements which in turn influence the firm yield of the reservoir.

\section{Acknowledgments}

None.

\section{Conflicts of interest}

There is no conflict of interest between the authors.

\section{Funding}

None.

\section{References}

1. Falkenmark MA, Mikulski R. The Key Role of Water in the Landscape System: Conceptualisation to Address Growing Human scenery Pressure. Geojournal. 2004;33(4):355-363.

2. José NBA. Modeling the Yield-Evaporation-Spill inthe Reservoir Storage -Process: The Regulation Triangle - Diagram. Water Resources Management. 2010;24:3487-3511.
3. Linsley RK, Franzini JB. Water-Resources Engineering. $3^{\text {rd }}$ edn. USA: Mcgraw-Hill, Blacklick, Ohio; 1979.

4. Gupton GW. Sculpt for reservoir systems, A Incident Analysis. Evasion Model. Contingency Analysis (CA). 1996;45-56.

5. Rafecas W, Mosler H, Dietz B, e al. Use of a Monte-Carlo Based Stochastic Matrix for 3D Iterative Rebuilding of Madpet-Ii Data. Nuklearmedizin, Klini-kumRechts Der Isar, Techn-ische University at Mounchen, Is-Maninger Str. 22, 81675 Mounchen, Germany. 2004.

6. Rosenberg U, Werman D. Representing Local Motion as a Probability Distribution Matrix and Object Tracking. Establishment of Computer Science. The Hebrew University Jerusalem, Israel. 2004.

7. Henrichs T, Joseph A. Critical regions: A model-based estimation of world water resources sensitive to global changes. Center for Environmental Systems Research, University of Kassel, Kurt-Wolters-Strasse 3, D-34109, Kassel, Germany. Aquat Sci. 2002;64(2002):352-362.

8. Arnell NW. Climate Change and Global Water Resources: Sres Emissions and Socio economic Scenarios. Worldwide Environmental ChangeHuman andstrategy Dimensions. 2004;14(1):31-52.

9. Kundzewicz ZD, Mata LK, Arnell NR, et al. Freshwater resources and their management. Fourth Assessment Report of the Inter - governmental Panel on Climate Change. Cambridge University Press, Cambridge, UK. 2007;172-209.

10. Dukiya JI. Spatial Scrutiny of the Impacts of Kainji Hydropower Resevoir on the Down Stream Communities an Overview. A Journal of Geoinformaticsand Geostatist. 2013;204(4):105-113.

11. Dockstein H. Selection of multi - objective techniques for a water resources problem and analysis under uncertainties. American Society of Civil Engineers. New York; 1984. 